\title{
The Child and the Fairy Tale: The Psychological Perspective of Children's Literature
}

\author{
Koutsompou Violetta-Eirini (Irene)
}

\begin{abstract}
Once upon a time...Magic slippers, dwarfs, glass coffins, witches who live in the woods, evil stepmothers and princesses with swan wings, popular stories we've all heard and we have all grown with, repeated time and time again. So, the main aim of this article is on the theoretical implications of fairy tales as well as the meaning and importance of fairy tales on the emotional development of the child. Fairy tales have immense psychological meaning for children of all ages. They talk to children, they guide and assist children in coming to grips with issues from real, everyday life. Here, there have been given general information concerning the role and importance of fairy tales in both pedagogical and psychological dimensions.
\end{abstract}

Index Terms - Children, development, everyday issues, fairy tales, psychological perspectives.

\section{INTRODUCTION}

Stories are important in everyone's lives and most important to children's lives. They gain a sense of who they are through narratives, the telling of stories to themselves and others about what has happened to them. By extension, they form their identities through integrating their unique, personal family histories with the legends of the culture. Because fairy tales and myths follow the heroine or hero as they go through periods of darkness to transformation, these classic stories may be said to encode patterns that enable the restoration of vibrant functioning. This article major purpose is to provide the reader with vital information as far as the significance of fairy tales is concerned and show the impact of fairy tales through the lens of psychology.

\section{DEFINITION AND Characteristics OF THE FAIRY TALES}

It is true that at times there have been attempts to define children's literature, a branch of literature, which now has a separate existence, despite the reciprocity pointed out between adult literature and literature for children. Each definition takes into consideration the special characteristics of childhood. Rebecca J. Lukens [1], starting from the principle that children differ in terms of their experiences and not in form, concludes that the difference is based on the degree and not in kind. This is the reason that literature for children differs from the literature for adults in terms of the degree and not in kind. Besides, children's literature offers the same pleasure as that of adult's literature. Children need to enjoy a story, but the source of this pleasure is more limited

Manuscript received August 23, 2016; revised December 5, 2016.

Koutsompou Violetta-Eirini (Irene) is with University of East London, UK (e-mail: violettairene_koutsompou@yahoo.com). given that their experience is more limited, since children fail to understand some concepts because of their complexity. For this reason, the expressions should be simpler, both in language and format. The stories have an immediacy, much of the digressions are avoided and the relationship governing the acting persons with the action is quite evident. The relationships that govern the acting persons, whether these are the acting or situational subjects or values are also more distinct. Children prefer the literal discourse more than adults, while they are more receptive and prone to imaginary situations. Having found that there are distinctive features in books for children, Peter Hunt [2] concludes that textual features are unreliable. In fact he believes that children's literature is inferior to adult literature.

It has been certainly clarified that, when we talk about children's literature, we do not mean the total number of books that are marketed for kids, because Para literature or texts of low or of questionable aesthetic value, can also be included in these. These texts have presumably a meager vocabulary and no specific purpose, apart from the fact that they intend to please and incidentally to have a kind of an emerging didacticism. They are often fond of profanity. On the contrary, it is the art of writing, which is cultivated by adults and aims principally at children-whether this is something being consciously sought by its creators or not. In other words, it is the set of aesthetically justified texts, which can contribute to both children's entertainment and spiritual cultivation, i.e. the development of the ability to perceive beauty, the maturation of personality and shaping the freedom of thought. Besides, children's literature includes

a) Texts of original production,

b) Critical texts, which are part of the wider field of literary theory and criticism and c) Tasks, which are interpretatively and instructively close to the original production of children's literature. This special branch of literature has seen a significant growth over the last years on a global scale, either as an original production or as a study of this production. The term inevitably leads to a partition of literature. Thus, on the one hand, its two sections seem to be independent: Children's literature or better Literature for children, as it is preferred, and Literature for adults. On the other hand, however, it seems that these two areas are in constant communication and close relationship, because children's literature is also read by adults, who often act as censors and they accordingly allow or prohibit children from a particular reading and they feed into one another to establish a reciprocal relationship, since texts that are written for children can be transformed into texts for adults and vice versa, texts for adults can be adapted for children. A classic case is that of the Homeric poems, whose adaptations are of unreliable quality or the Tale without a 
Name by Pinelopi Delta and the homonymous theater play by Iakovos Kampanellis. At least most scholars, in their efforts to define the term Children's Literature, follow the same path. They initially identify the general term of Literature, they continue in exploring the question "What is a child" and, finally, they attempt to define children's literature. In the second question, they attempt to detect childhood characteristics, which are long-standing and intercultural. Therefore, according to Isabelle Jan [3], literature for children exists only from the moment that the child - adult distinction has been made. According to this practice, Hunt [2] detects some distinctive features such as spontaneity, acceptance of intellectual excellence, psychological compulsions, emotional attachment to mature persons, inability to abstract thinking, the degree of distraction that differs from the adult counterpart. These features make children more easily adaptable than adults.

In fact, McDowell Miles [4] resorts to the features of a children's book, as he attempts to define children's literature. In particular, he writes "children's books are generally shorter and tend to favour active rather than passive behavior with dialogues in episodes rather than in descriptions and introspections. The child-protagonist is the norm. Conventions are greatly used. The story develops in clear (= strictly defined) ethical formations that many adults are unaware of. Children's books tend to be optimistic rather than discouraging. The language is child oriented. The plot is shaped under a distinct order and the probability is often rejected. Finally, one could talk about a magical and imaginary atmosphere, as well as simplicity and an adventure". In his efforts to identify the features of the literature for children, Perry Nodelman [5], finds that children's literature

- is simple,

- focuses on action,

- addresses childhood,

- expresses the views of the child,

- is optimistic,

- tends to be imaginary,

- is a form of a sacred romance,

- involves innocence,

- is instructive,

- is repetitive,

- tends to balance the ideal and instructive.

\section{The Aesthetic ANd Pedagogical Role of CHILDREN'S LITERATURE}

Teaching children's literature is obviously in direct connection with its content, in other words, how it is defined. Here, we encounter two views. The first includes those definitions that converge and accept the priority of the artistic, aesthetic element in texts, therefore they have the sole objective to please the child-reader (and the adult). The second gives priority to other educational goals and accepts the pedagogical character of children's literature. In her transactional theory, Louise Rosenblatt [6] describes the experience with literature as an aesthetic situation, an interaction with literature, in which experience is the interesting factor. At the same time, she also touches on effective reading, whose main objective is acquiring information. F. J. Harvey Darton [7] believes that children's literature was created in order to offer children a source of pleasure and not necessarily to teach and nourish them. Margery Fisher [8] also rejects the social functioning of children's literature, arguing that we should not expect books for children to include social considerations and moralistic lectures, because they are artistic works, which should touch on their imagination under their own terms. Peter Dickinson [9] also takes an evaluating stand, as he does not accept that all readings that do not involve some obvious aesthetic or pedagogical value is rubbish. Sheila Egoff [10] maintains the same notions, when she expresses the view that the children's literary book should aim at offering pleasure and not education to the child-reader. She accepts that modern children's literature, as it is primarily represented by High Fantasy texts and by the best realistic novels, has a wide range of topics and a philosophical depth. However, she claims that the main aim is to entertain rather than to educate the child. Thus, the final conclusion is that the aim of children's literature is purely recreational and not pedagogical. Nicholas Tucker [11] also opposes the view that the children's literary book communicates knowledge and educates. He argues that literature, according to others theoreticians, is free from the pedagogical features it must be governed by. However, despite these observations he does not exclude the "pedagogical conventions', which are mainly due to the children's limited perceptual ability. John Donovan [12] also highlights the social and pedagogical role of children's literature. Maria Tatar [13] also accepts the pedagogical nature of children's literature. Moreover, both Perry Nodelman [5] and Rebecca Lukens [1] accept the pleasure the reader feels while reading children's literature. The first one, who refers to the delight of a literary text, draws up a list of ' pleasures $1 /$ cases of delight in literature. Basically, he detects the pleasure of the text in the dialogue among readers and the texts and among readers and other readers with reference to the texts, without referring to the pedagogical role of children's texts. Rebecca Lukens [1] admits that literature (in general) informs, but it also offers much more. She specifically writes "We choose literature that promises fun and often provides us with the possibility to escape". In general, literature offers emotion and knowledge. Referring to the role of literature, she argues that literature captures the human emotions, equips with experiences, reveals the fragmentation of life, helps focus our attention on the essential aspects, reveals the social institutions and clarifies our reactions to them and manifests the nature as a force that affects humans. In contrast, several theorists, such as Michele Landsberg [14], accept the pedagogical role of the children's literary book, identifying a moral and emotional dimension. Aidan Chambers [15] identifies the pleasure of the text in the discovery of standard events, in understanding of the characters and ideas, in the perception of images and in deciphering the language interaction, therefore in a total conception of the text both as format and as content. John Stephens thinks that the children's text aims at fostering positive thoughts of some social and cultural values in a child that are shared by the author and the audience. The views expresses about literature by Richard Hoggart [16], who does 
not discern any pure aesthetic value in literature, but identifies human experience in the texts, are quite interesting. Joan I. Glazer [17] supports that the children's book contributes in the psychological development and education of the child, but also in the formation of aesthetic criteria. However, Grigorios Xenopoulos [18] supports the coexistence of the emotional and pedagogical purpose of the children's book. In the preface of the direct edition of "My Little Sister", he mentions that the book is not just an educational novel, but also a literary work". We also share this view, alternatively the children's book would be a kind that is becoming obsolete. Moreover, Loti Petrovic-Androutsopoulou [19] also supports that children's literature "like it or not, functions in an educational way".

\section{THE IMPORTANCE OF TRADITIONAL LITERATURE FOR CHILDREN}

Traditional children's literature (legends, myths [and tale]) offer children a better understand the world. Each story is based on a culture and the world of the culture is unlimited [20]. The narration or reading of legends, myths, and fairy tales is a way of nurturing the child's soul and humanism. The understanding of the world grows as children understand the early cultural traditions, learn about the culture and read a variety of myths, learn to appreciate the culture and art of other people, according to Donna E. Norton [21]. Without spiritual knowledge, children-readers may not realize the dissemination of the culture. The similarities found in texts of traditional children's literature indicate movements of people (migration and conquest). They even show that all people have the same needs and the same problems. In fact, some tales are almost the same. At the same time, traditional myths encourage children to imagine that people from all over the world care about the good, the courage, the benefaction and the industry. In his book "The Magic of Fairy Tales" ("The meaning and importance of fairy tales") Bruno Bettelheim [22] strongly argues about the use of traditional myths by children. In his psychoanalytical approach to myths, Bettelheim [22] argues that nothing provides greater wealth to children as traditional children's literature. To support his view, he argues that traditional children's literature help children learn about human progress and possible problem solving. This is because myths undoubtedly and briefly involve some problems that the child can understand. In addition, myths involve a moral behavior of heroes. Thus, children can learn that it is inevitable for one to fight against the difficulties of life and that these can be overcome. Traditional children's literature also includes characters that are good and bad. Simple and good characters allow the child to identify with the good and reject the bad. The child sympathizes with the deserving characters, "participates" in his fights, learning that while he/she may encounter difficulties or be rejected by someone, he/she would be helped and guided when needed [23]. Traditional children's literature, tales in particular, which are rapidly developed and include a dramatic plot and an easy identification with the good character, belongs to the type of literature that "speaks" more to listeners or readers and gives pleasure. They believe that the environment of this literature's heroes/heroines is similar to their own environment.

\section{FeATURES OF THE FAIRY TALE}

The folk or alternative fairy tale is the most preferable type of discourse in children. It is a comforting discourse intended for narrative or storytelling designed to distract someone from any concerns. Gradually, the word came to mean what we actually mean today, since all the imaginary narratives aimed at entertaining the listeners and carrying them to dark away lands were included [23]. We can therefore define the fairy tale as an imaginary tale, which moves into a supernatural and magical world and is designed to satisfy the listener. Given that fairy tales differ from other types of literature, their features are found mainly in the plot, characters, setting, theme and genre [23]. Specifically:

1. Its world: The fairy tale is a completely imaginary narrative, whose key objective is to satisfy and to entertain. Its world is completely fictional, it lacks plausibility and neither natural laws nor human determinism apply. When the hero is in danger, he/she is saved by intervening supernatural powers: The symbolic scenography found in fairy tales is not described in detail, because there is no need for a detailed description, if, for example, someone immediately knows that something will happen in the magic forest. Space and past tense are soon outlined, with space indicating a natural stage setting and time a distant and elusive past. After the description of scenery, the heroes are immediately identified and conflicts are soon developed.

2. The folktale is distinguished by the generality of people, place and time. The "fairy" story unfolds in an indefinite time and place. The virtually anonymous heroes have been named based on their characteristics or their attire, etc.: Little Red Riding Hood, Cinderella, Snow White, Tom Thumb, Little Briar Rose (Sleeping Beauty) etc. They are clearly symbolic names, which reflect the world of folktale heroes, or they are descriptive, as we have seen, and rely on the heroes' external or natural qualities.

3. Everything that happens in a fairy tale ranges in extreme situations. Everything is either too big or too small or too ugly or very beautiful etc

4. More often than not its heroes are described by monstrous features and physical malformations and their physical attributes reflect their inner world. These teratogenesis and malformations certainly reflect a social reality, full of anxiety, fear, prejudices and superstitions. In fairy tales, the characters are not described in a comprehensive way as compared to other respective texts (novels), because the narrator doesn't have the time to develop them in a global way. Therefore, the characters in fairy tales are virtually of a symbolic and shallow nature, i.e. they have a limited range of personal characteristics and do not show any change during the development of the fairy tale. They are quite easily standardized into good and evil. Young heroines are polite and amiable. The youngest son is honored, is gentle and not selfish at all, if not considered inept. Indeed, children easily identify the good and bad character in fairy tales.

5. The story is basically structured around the archetypal figure of good and evil, where evil temporarily outweighs the 
good only to prevail in the end.

6. Its aim is not to teach, advice or urge, as opposed to myth and proverb, whose aim is learning a moral lesson. Its moral nature is certainly distinct, because it stems from the moral conscience of people, but the main purpose of the fairy tale is the delight and the entertainment through narration.

7. Conflicts and action abound in fairy tales. The nature of oral tradition gives them an imperative feature, while heroes are quickly transferred into action and this is present from the first lines of a fairy tale. The conflicts between characters representing the good and those representing the evil are totally classic in fairy tales. The action that is observed in fairy tales has drawn the attention of many scholars. All fairy tales have a similar end, beginning and plot.

\section{CATEGORIES OF FAIRY TALES}

The study of the fairy tale led to their categorization. According to Loukatos [24], the Greek fairy tales are divided into the following categories

1) Magic Tales: refer to giants, dragons, witches, etc. having profound magical evidence.

2) Narrative Tales: their world is the human society. They resemble novels that are known to us.

3) Religious or Canonical Tales: they are inspired by the lives of the saints.

4) Jocular or Satirical Tales: They refer to the sufferings of inept characters, outwitting dragons etc.

Vladimir Propp [25] is the first who studied the tripartite structure and technique of the Russian fairy tale:

- A brief introduction, which prefigures and prepares the listener or the reader.

- Then, there is the narration of the fairy tale itself, which consists of a variety of motifs.

- The end and the conclusion of the story follows, which always contains the hero's victory.

In his work "Morphology of the Fairy Tale", Vladimir Propp [25] finds 31 functions, as he defines the fixed and unchanged time features of folktales. He indicates that the structure of folktales is organized on the basis of these functions. These functions are allocated in cycles, based on the acting persons,

- Circle of the competitor,

- Action cycle of the donor,

- Action cycle of the assistant and

- Action circle of the Princess (the intended person) and her father,

- Action cycle of the sender,

- Action cycle of the hero and finally

- Action cycle of the false hero.

The function of violating an order plays a key role in the development of the story of the fairy tale, which is considered to be the relating disobedience of Adam and Eve in our Holy Bible.

\section{THE IMPORTANCE OF THE FAIRY TALE}

It is true that children, particularly those of younger ages prefer to read folktales. This is due to the fact that:
- They cultivate the imagination,

- They bring the child in contact with folk tradition,

- From a pedagogical point of view, the tale is suitable for the education of children, because primitive people's way of thinking, as it has been proven by anthropological studies, is very close to the introductory thought of children,

- The tale nurtures both the national as well as the global and, universal thought. These are supported by the distinctive features of super-localization and continuity.

The tales consist of universal truths and reflect the values of the time periods and societies from which they are derived. Many of these have still have a significant value, even nowadays. The characters, their actions and their reward lead to the development of moral issues. The good defeats the evil, justice triumphs, the non-arrogant is lucky in love, intelligence overcomes physical strength, while kindness, diligence and hard work leads to reward. The jealous queen, such as in the alternative tale of Eugenios Trivizas "the Dona

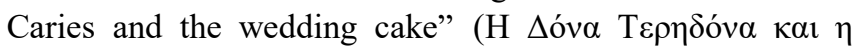
$\gamma \alpha \mu \eta \dot{\lambda} 1 \alpha \tau o u ́ \rho \tau \alpha$ ), is punished, the foolish King loses part of their property or a child, usually his daughter etc. The universality of these issues demonstrates that people all over the world maintain similar ideas and beliefs, such as, for example, wit is superior to physical strength or fools lose their property.

\section{The FunCtION OF FAIRY TALES: The PERsPeCtIVE OF PSYCHOLOGY}

The majority of fairy tales deals with a series of recurring concerns, such as socialization, emotional independence and the problematic relationships each child faces in the environment during his/her psychosocial development. According to the psychoanalytic approach, the thematic areas, which most fairy tales deal with by using a symbolic language and transfer are the following [22]:

- Fear of being abandoned by parents

- Conflicts within the family, sibling rivalries

- Social maturity, process towards autonomy

- Acceptance of negative and positive traits of self and parents

- Acquisition of gender identity-problems in puberty

- Parent-child relationships - (mother-daughter, father-son, daughter- father)

- Emotional integration

All good tales are meaningful on many levels and help the child build his/her internal and external reality.

Without the need of rendering a moral lesson or interpretation, the child intuitively discovers the hidden meanings of the fairy tale on his/her own, which are meaningful to him/her at a given moment, depending on the stage of his/her psycho-emotional development [22]. In an almost magical way, we dare say, fairy tales identify the maturational processes in the individual development of each child and provide a fertile ground that allows the connection with the facilitative environment [26] of the child. As the fairy tales deal with key issues and emotional childhood experiences, they easily stimulate the mechanisms of projection and identification [27]. These emotional processes, operating at a symbolic-imaginary level, play an important 
role in the structuring of the child's psycho-emotional experience. The stories of fairy tales expressed through language by transfer and symbolic representations, facilitate the development of symbolic thought, the representative abilities and the mental processing of life events at a fantasy-level [28], which form the basis for the development of creative thought and emotional intelligence [29]. The narration of fairy tales contributes highly to the development of children's creative imagination, which is fundamental to their psycho-emotional health. Having imagination means enjoying inner wealth, a relentless and spontaneous flow of images and viewing the world in its entirety [30]. In the dreamy world of the fairy tale, where everything unfolds in an intermediate space between fantasy and reality, the child's magic thought finds an appropriate way out. The structure of fairy tales allow children to move into a dreamy world without restrictions and cancellations. At the same time, through the mechanisms of identification and projection, the child has the ability to identify, express his/her negative feelings, to give importance to personal traumatic experiences and, ultimately, to look for and find a meaning in his/her life [22]. In a comprehensible and clear manner, the fairy tales answer the fundamental questions of children and keep their initiatory character, as they transfer important knowledge and information about life [28].

The stories of fairy tales enhance the children's faith in their ability to build their own personality rather than the external adversities, inner conflicts or deadlocks experienced. The enchantment of fairy tales lies in this very potential. Among the multiple functions they perform, fairy tales offer an effective way for children to express and illustrate their existential-developmental anxieties, the inner and external conflicts and their doubts [27]. Fairy tales give meaning to the inner and external conflicts experienced by children in a complex, incomprehensible and hardship-filled world. With the positive outcome of their stories, fairy tales help in appeasing the fears experienced at various developmental stages, in reassuring that the unknown can become known and contribute to the establishment of a wider, positive perspective about life, while answering a child's deep need for justice [22].

The complexity of human nature, in which both good and evil coexist, is well identified in fairy tales. The figures in fairy tales are good and bad at the same time, as we all are in reality. But since polarization dominates the child's mind, it also dominates fairy tales. A person is either good or bad, never anything in between. For example, one sister is virtuous and industrious, the others are vile and lazy, one parent is good, the other evil. The juxtaposition of opposite characters permits the child to easily comprehend the difference between the two, which he could not do if these figures were closer to real life. Furthermore, a child's identification choices are based, not so much on right versus wrong, but mainly which person they like and which they dislike. The simpler and more straightforward a good character is, the easier it is for a child to identify with it and to reject the bad character. Typically, the child identifies with the good hero not because of his goodness, but because the child is positively attracted to the hero. However, due to the abundance of fairy tales with various heroes (good and bad) and the complex conditions they experience, the child is also able to identify with negative models-heroes, who escape from their parents' moral limitations, since this identification answers to certain needs of their psycho-emotional development.

Some of the children's basic desires, feelings, impulses and needs, which are often not expressed and are suppressed into the world of everyday life by the parental standards are favorite topics of fairy tale stories. In the safe space of imagination, children can come in contact with this wide range of 'banned', dark emotions-reactions and negative expressions of life, of their self and others, without having to suffer the painful consequences of everyday life or disrupting the sense of reality and the relationship of children with significant persons by the adult world.

\section{Positive EfFects of NARRAtive FAIRY TALES}

The different narrative means such as stories, metaphors, myths and fairy tales have a significant psycho-educational effect in child development. The storytelling techniques can contribute by activating a variety of psychological processes, such as imagination, memory, attention to the expansion of listener's active socio-moral receptivity [31]. Egan [32] argues that the classic fairy tales have an important effect on engaging the imagination of young children in the classroom, while the dramatization of stories can function as an early form of teaching and learning within the school context. Research has shown that storytelling as well as the children's contact with a wide range of texts from the traditional literature, contributes to:

- Better self-awareness and awareness of others, development of emotional intelligence [33]

- Development of healthy self-concept, sense of identity [34]

- Enhancement of imagination [35],

- Development of human morality [36]

- Enhancement of cultural sensitivity [37] when children are exposed to storytelling from various cultural contexts

It is noted, however, that few surveys have been conducted in this area, since it is difficult to study the influence of the ancient tradition of the storytelling art form on the mental development of children and the development of learning skills strictly by using scientific criteria [28]. If we review the overall history of oral storytelling, in a broader perspective, we will see that two kinds of storytelling emerge, with the purpose of mental health: one that seeks to maintain mental health and acts in a preventive level-and a second that aims at restoring mental health and functions as a therapeutic mean [38].

\section{CONCLUSION}

Summing up, we would say that the fairy tale is the foremost form by which the child learns to read his mind with the language of the images-symbols which is the only language that allows the understanding before mental maturity is achieved. As reported by Campbell [39], the folktale is the primer of the image of the soul. The special contribution of fairy tales in the psychosocial development of children is seen in the timeless message they convey: the 
difficulties, often unexpected and unfair, inevitably accompany the human path, but if one could face them with courage, then he dominates the obstacles and is declared a winner.

Understanding the dynamics occurs in the fairy tale hero/heroine's journey, which typically leads from misery to the highest development, could reveal to us as therapists and youth workers, some ways to help children but also adults, in their uphill path of their life. However, it is necessary to remember that no technique or method can fully answer the multidimensional needs of children whether these are social, educational, emotional, cognitive or biological. Hence, fairy tales are supplementary to the range of methods used in psycho-educational or therapy intervention framework. At this point, it should be mentioned that the above study is part of a research on storytelling/fairy tales and its benefits in changing unhealthy eating habits in children. In fairy tales there is rich information on food which can help parents control themselves as well as finding ways to bond positively with their children through food practices.

\section{REFERENCES}

[1] R. Lukens, A Critical Handbook of Children's Literature, HarperCollins College Publishers, New York, 1995.

[2] P. Hunt, International Companion Encyclopedia of Children's Literature, London: Routledge, 1996.

[3] I. Jan, On Children's Literature, Schocken Books, First Edition, 1974.

[4] M. McDowell, "Fiction for children and adult: Some essential differences," Children's Literature in Education, 1973.

[5] P. Nodelman, The Pleasures of Children's Literature, New York \& London: Longman, 1992.

[6] L. Rosemblatt, The Reader the Text, the Poem. The Transactional Theory of the Literaty Work, Carbondale and Edwardsville: Southern Illinois University Press, 1994.

[7] F. Darton, Joseph Harvey Children's Books in England: Five Centuries of Social Life (Cambridge Library Collection - Literary Studies), Cambridge University Press, Reissue edition, 2011.

[8] M. Nikolajeva, The Rhetoric of Character in Children's Literature, Maryland: Scarecrow, 2002.

[9] M. Nikolajeva, Aesthetic Approaches to Children's Literature: An Introduction, Scarecrow Press, 2005.

[10] S. Egoff and J. Saltman, The New Republic of Childhood: A Critical Guide to Canadian Children's Literature in English, 1990.

[11] N. Tucker, The Child and the Book: A Psychological and Literary Exploration (Canto original series), Cambridge University Press, 1990.

[12] J. Donovan, I'll Get There; It Better Be Worth the Trip, 40 ${ }^{\text {th }}$ Anniversary Edition, Woodbury: Flux, 2010.

[13] M. Tatar, Off With Their Heads!. Fairy Tales and the Culture of Childhood, New Jersey: Princeton UP, 1992.

[14] M. Landsbergs, Michele Landsberg's Guide to Children's Books, Penguin Books Australia, 1986.

[15] A. Chambers, The Reading Environment, How Adults Help Children Enjoy Books, Exeter: Thimble Press, 1999.

[16] R. Hoggart, The Uses of Literacy, Penguin Books Ltd., 1969.

[17] J. Glazer, Literature for Young Children, New Jersey: Prentice Hall, 1991.

[18] J. I. Glazer, An Introduction to Children's Literature, New Jersey: Prentice Hall, 1997.

[19] L. Petrovic-Androutsopoulou, Children's Literature in our Times, Athens: Kastaniotis, 1990.

[20] D. Wolkstein, Treasures of the Heart, Random House Inc., 2002.

[21] D. E. Norton, Through the Eyes of a Child, An Introduction to Children's Literature, MacMillan, 3rd edition, 1991.

[22] B. Bettelheim, The Uses of Enchantment: The Meaning And Importance of Fairy Tales, New York: Vintage Books, 1989.
[23] J. Glazer, Literature for Young Children, New Jersey: Prentice Hall, 1991.

[24] D. Loukatos, An Introduction to Greek Ethnography, Educational Foundation of National Bank, 1992.

[25] V. Propp, The Morphology of Fairy Tale, Trans. Aristea Parisi. Athens: Kardamitsas.

[26] D. Winnicott, Maturational Processes and the Facilitating Environment: Studies in the Theory of Emotional Development, Karnac Books, 1996.

[27] M. L. Von Franz, The Interpretation of Fairy Tales, Boston: Shambhala Publications, 1996.

[28] H. Kourkoutas, Psychoanalytic Approach of Fairy Tales and the Use of Children's Stories in Psychotherapy and Special Education, Athens: Topo.

[29] J. M. Gottman and J. DeClaire, The Heart of Parenting: How to Raise an Emotionally Intelligent Child, Bloomsbury Publishing PLC, 1997.

[30] M. Elliade, Images and Symbols: Studies in Religious Symbolism, Harvill Pr, 1st edition, 1961.

[31] L. S. Vygotsky, Vygotsky and Creativity: A Cultural-Historical Approach to Play, Meaning Making, and the Arts, Peter Lang Publishing Inc., 2010.

[32] K. Egan, Children's Minds: Talking Rabbits \& Clockwork Oranges, NY: Teachers College Press, 1999.

[33] R. Mello, "The power of storytelling: How oral narrative influences children's relationships in classrooms," International Journal of Education \& the Arts, vol. 2, no. 1, 2001

[34] V. G. Paley, The Boy Who Would Be a Helicopter: The Uses of Storytelling in the Classroom, Cambridge, MA: Harvard University, 2001.

[35] K. Gallas, The Languages of Learning: How Children Talk, Write, Dance, Draw, and Sing Their Understanding of the World, N. Y: Teachers College Press, 1994.

[36] J. Zipes, Fairy Tale as Myth, Myth as Fairy Tale, Lexington: University of Kentucky Press, 1994.

[37] A. McCabe, "Cultural background and storytelling: A review and implications for schooling," The Elementary School Journal, vol. 97, no. 5, pp. 453-473, 1997.

[38] S. Pelasgus, The Secrets Fairytale, An Apprenticeship in the Art of Oral Literature and Storytelling, Athens: Metexmio, 2007.

[39] S. Doulamis and A. S. Antoniou, "The charm of fairy tales: Their Use and Importance in the field of special education," in Proc. 2nd Hellenic Conference of Educational Sciences, Athens, May 2010.

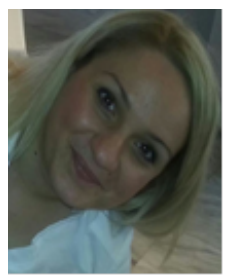

Koutsompou Violetta-Eirini (Irene) holds a bachelor's degree in English language/literature and psychology from the State University of New York, USA, a master's degree in English and comparative literature from University of Indianapolis, USA, an accredited certificate in TEFL from Hellenic American University, a professional diploma in counseling psychology from City Unity College, Athens, Greece and a master of science degree in psychology from the University of East London, UK. She has attended seminars and specializes in psychoanalysis and Jungian psychology at the Carl Gustav Jung Institute, in Zurich. Ms. Koutsompou has taught as an invited lecturer in colleges in Greece where she presented her thoughts and theory about children's literature and development and loss in every aspect of life. Her areas of interest and concentration are psychology of child development, children's literature and its impact on the cognitive and emotional development, depression, grief and loss, second language acquisition, postmodern literature, women's psychology and writings, book editing and writing. She has worked in private language institutions in Greece since 2005; she was interested and worked with children with special learning difficulties such as dyslexia, as well as with children with behavioral problems in the language classroom. She has presented her work in many conferences in Greece and abroad and in 2013 she was awarded a Certificate of Excellence for her research in postnatal depression from the committee of the 2nd psychology conference of City Unity College in Greece. She is a graduate member of the British Psychological Society, an Affiliate International member of the American Psychological Association, member of the TESOL Greece, of the IRED. 